\title{
A TEORIA GERAL DO CRIME: CONCEITO E ELEMENTOS
}

\author{
THE GENERAL THEORY OF CRIME: CONCEPT AND ELEMENTS
}

\author{
Augusto Rostirolla ${ }^{1}$ \\ José Henrique Gottschalk Pereira ${ }^{2}$ \\ Felipe Rodrigo Kipper ${ }^{3}$ \\ Daniel de Azevedo Crespo ${ }^{4}$ \\ Jeronimo Prade da Silva ${ }^{5}$
}

RESUMO: Este artigo tem como objeto o estudo da teoria geral do crime, mais especificamente, o conceito de crime e seus elementos. Foram analisados os aspectos formais do crime, do ponto de vista doutrinário e legal, por meio de pesquisa bibliográfica, a fim de definir quando uma ação ou omissão se torna um crime e quais seus elementos constitutivos.

Palavras-chave: Teoria geral do crime. Conceito de Crime. Elementos do crime.

ABSTRACT: This article aims to study the general theory of crime, more specifically, the concept of crime and its elements. The formal aspects of the crime were analyzed, from a doctrinal and legal point of view, through bibliographic research, in order to define when an action or omission becomes a crime and what are its constitutive elements.

Keywords: General theory of crime. Crime concept. Elements of crime.

\section{INTRODUÇÃO}

Este trabalho tem por objetivo abordar de forma direta a teoria do crime, seu conceito formal, material e analítico e os elementos essenciais para sua caracterização, como fato típico, ilicitude e culpabilidade.

\footnotetext{
${ }^{\text {I }}$ Formado em Direito pela Universidade de Santa Cruz do Sul - UNISC/RS.

${ }^{2}$ Formado em Ciências Jurídicas e Sociais pela Pontífice Universidade Católica - PUC/RS.

${ }^{3}$ Formado em Direito pela Universidade de Santa Cruz do Sul - UNISC/RS.

${ }_{4}^{4}$ Formado em Engenharia Mecânica pela Universidade Federal do Rio Grande do Sul - UFRGS/RS.

${ }_{5}^{5}$ Formado em Tecnologia em Marketing pela UNINTER.
} 
Sua finalidade é esclarecer o que define uma conduta criminosa de acordo com o ordenamento jurídico vigente e entender por que este é o entendimento é adotado.

O primeiro capítulo tem o objetivo de analisar a teoria do crime como um todo, seu conceito, analisando as teorias bipartida e tripartida.

No segundo capítulo são observados os elementos que constituem o crime de forma mais aprofundada, analisando quais os elementos necessários para caracterizar uma ação ou omissão como crime.

\section{CONCEITO DE CRIME}

O conceito de crime pode ser estudado sob a ótica formal, material ou analítico.

O critério formal considera crime qualquer conduta que colida contra a norma penal, considerando todo ato humano proibido pela lei penal. Mas não apenas isso, pois o tal critério observa o ponto de vista do legislador que nos direciona para o que é crime em relação a infração penal, sendo ele, de acordo com o legislador, qualquer fato que comine em pena de reclusão ou detenção.

O aspecto material é toda ação ou omissão que fere um bem jurídico penalmente tutelado. Esse critério leva em consideração todo mal causado as vítimas,titulares de direitos e garantias constitucionais tuteladas pelo direito penal. Essaforma e voltada para as políticas criminais que auxiliam o legislador a tipificar determinadas condutas que exponham a perigo qualquer bem jurídico tutelado, desdeque observado o princípio da intervenção mínima do estado, em que o direito penal é ultima ratio só se preocupando com causas de relevante com alto grau de periculosidade social, em que outros ramos do direito não possam mais observar.

Damásio de Jesus entende que o critério material, é a base pela qual o legislador se fundamenta para criar o critério formal:

É certo que sem descrição legal nenhum fato pode ser considerado crime. Todavia, é importante estabelecer o critério que leva o legislador a definir somente alguns fatos como criminosos. É preciso dar um norte ao legislador, pois, de forma contraria, ficaria ao seu alvedrio a criação de normas penais incriminadoras, sem esquema de orientação, o que, fatalmente, viria lesar o 
jus libertatis dos cidadãos. (Jesus, Damásio - direito penal - parte geral, 2015, p.193).

O critério analítico, como o próprio nome já diz, analisa os elementos principais do crime, sem lhe causar rupturas, estudando-o como unitário. Seus elementos são o fato típico, a ilicitude, a culpabilidade e a punibilidade. Vale ressaltar que a punibilidade, de acordo com grande parte da doutrina, não deve ser considerada característica do crime, mas sim o resultado do delito, uma vez que pela ação danosa se tem a punição.

Essa posição quadripartida é claramente minoritária e deveser afastada, pois, a punibilidade não é elemento do crime, mas consequência da sua prática. Não é porque se operou a prescrição de determinado crime, por exemplo, que ele desapareceu do mundo fático. Portanto, o crime existe independentemente da punibilidade (DAMASIO, 2015, p.201).

O conceito analítico de crime é dividido em duas vertentes: o bipartido e o tripartido.

A teoria tripartida entende que o conceito analítico de crime é o fato típico, ilícito e culpável, sendo a culpabilidade um elemento constitutivo de crime, visto quesem a culpabilidade não há crime. Nos dizeres de Cezar Roberto Bitencourt o sistema clássico formou essa teoria, formulando um crime com uma conduta típica ilícita e culpável, tendo dentro de si o dolo e a culpa, que mais tarde tem como concorrente a teoria finalista que mudava o dolo da culpabilidade para o fato típico. Mesmo o criador dessa teoria ainda defendia o conceito tripartido.

O próprio Welzel, na sua revolucionária transformação da teoria do delito, manteve o conceito analítico de crime. Deixaesse entendimento muito claro ao afirmar que o conceito $d$ culpabilidade acrescenta ao da ação antijurídica tanto de uma ação dolosa como não dolosa um novo elemento, que é o que a converte em delito. Com essa afirmação Welzel confirma que, para ele, a culpabilidade é um elemento constitutivo de crime, sem a qual este não se aperfeiçoa. (BITENCOURT, p.278).

Já a teoria bipartida é composta por fato típico e ilícito. Sendo considerados os seguintes sub-elementos: conduta, resultado, nexo de causalidade entre o resultado ea conduta e a tipicidade, além de necessitar que seja um fato ilícito, não estando empossada 
das causas de excludente de ilicitude, a culpabilidade seria apenas um pressuposto para que a pena fosse aplicada.

Culpabilidade é a reprovação da ordem jurídica em face de estar ligado o homem a um fato típico e antijurídico. Reprovabilidade que vem recair sobre o agente, ensinava Aníbal Bruno, porque a ele cumpria conformar a sua conduta com o mandamento do ordenamento jurídico, porque tinha a possibilidade de fazê-lo e não o fez, revelando no fato de não o ter feito uma vontade contraria aquela obrigação, no comportamento se exprime uma contradição entre a vontade do sujeito e a vontade da norma. Portanto a culpabilidade não é requisito do crime, funcionando como condição de imposição da pena. (DAMASIO, p.197).

\section{ELEMENTOS DO CRIME}

Agora que entendemos a o conceito de crime e analisamos as duas principais correntes sobre os elementos constitutivos do crime (bipartida e tripartida), passamosa analisar cada um deles de forma separada.

\section{Fato típico}

O fato típico é a ação humana que se adequa especificamente ao elemento descrito na lei penal. O fato típico é fundamental para a criação de um crime, devendo ele ser observado primeiramente para só depois serem observados os outros elementos do crime, pois sem ele não há uma conduta que necessite da tutela do direito penal.

Para que haja fato típico, são necessários quatro elementos, a conduta, o resultado, a relação de causalidade ou nexo causal e a tipicidade.

A conduta é o primeiro elemento do fato típico, e nada mais é do que o comportamento humano, é a ação ou omissão do sujeito que da causa ao fato típico.

As condutas podem ser comissivas ou omissivas. As comissivas, também chamada de ação é o movimento humano que gera alguma mudança no mundo externo, a omissão em contrapartida é toda falta de ação necessária que desencadeia uma mudança no mundo externo. 
Além disso, as condutas podem ser classificadas em dolosas ou culposas. O dolo é toda vontade humana geradora de um resultado, enquanto a culpa a falta de uma vontade que gerou o resultado por imprudência, negligência ou imperícia.

Existem, ainda, hipóteses da exclusão da conduta, sendo elas o caso fortuito e a forca maior, atos ou movimentos reflexos ou coação física irresistível. O caso fortuito e a força maior são os casos em que não há previsibilidade além de ser inevitável, não estando no alcance da vontade humana. Os atos ou movimentos reflexos são as reações motoras causadas excitação dos sentidos, em que determinadaação é realizada sem a vontade do agente, como o sonambulismo ou hipnose. A coação física irresistível e quando o indivíduo não tem liberdade em suas açõessendo forçado fisicamente a realizar uma ação.

O segundo elemento do fato típico é o resultado. O resultado nada mais é do que a modificação no mundo exterior, causada pela conduta de um indivíduo. Embora a própria conduta já faça tal mudança, o resultado é a transformação criada pela conduta com seus efeitos, como explica Damásio de Jesus:

É certo de que a própria conduta já constitui modificações no mundo exterior. Todavia, o resultado é a transformação operada por ela, é o seu efeito, dela se distinguindo. (DAMASIO, p.283).

O resultado pode ser dividido em duas espécies, jurídico ou normativo. O resultado jurídico é toda a lesão ou perigo de lesão de um bem juridicamente tuteladopela lei, ou seja, é a mera desobediência a lei penal que vai gerar o resultado. O resultado naturalístico, também chamado de material, é a mudança no mundo exterior causada pela conduta do agente. Toda infração penal tem resultado jurídico, pois sempre há um bem jurídico que está sendo violado, mas nem sempre tem o resultado naturalístico que é derivado de um crime material.

O terceiro elemento do fato típico é o nexo causal. É a ligação entre a conduta realizada pelo sujeito e o resultado que foi gerado pela ação, ou seja, só se pode imputar sanção a uma pessoa se ela tiver gerado o resultado. $O$ ordenamento jurídico brasileiro 
aderiu a teoria da equivalência dos antecedentes, em que a ação comissiva ou omissiva será considerada, sendo que sem ela o resultado não aconteceria. Através dessa teoria deve-se analisar o crime do resultado para trás, para se chagarno que o causou.

Ainda há que se destacar que nos crimes classificados como de mera conduta ou os formais, em que não necessita da existência do resultado, não há o nexo de causalidade, pois este só ocorre como ligação entre a causas e o resultado. Se tais delitos não encontram resultado obviamente haverá relação causal.

O quarto e ultimo elemento do fato típico é a tipicidade, que nada mais é do que a adequação de uma conduta humana com relação à lei, se encaixados todos os itens comuns entre o fato no mundo real com o que a lei descreve haverá a tipicidade. $O$ método pelo qual se conecta a conduta do agente com o modelo descrito em lei é chamado de adequação típica e pode ser feita de forma direta ou indireta.

\section{Ilicitude}

A ilicitude é a contrariedade de uma ação ou omissão praticada por alguém em relação ao ordenamento jurídico, colocando em risco os bens jurídicos penalmente tutelados. A ilicitude pode ser formal, quando o fato praticado contraria o ordenamento jurídico, como material ou substancial, quando o conteúdo da ação delitiva analisa o comportamento sob o aspecto social.

Em face da recepção da teoria da tipicidade como indício de ilicitude, quando exercido o fato típico se prevê a característica ilícita. Mas essa presunção é relativa, pois um fato típico pode ser considerado lícito, desde que esteja amparado pelas causas de excludente de ilicitude, que são a legitima defesa, o estado de necessidade, o estrito cumprimento do dever legal, e o exercício regular de um direito.

\section{Culpabilidade}

A culpabilidade é o elemento chave nas discussões a respeito das teoriasbipartida e tripartida, visto que alguns doutrinadores entendem como sendo este elemento apenas pressuposto de pena enquanto outros acham ser um dos elementos construtivos do 
crime, visto que sem ele não há que se falar em delito. A culpabilidade determina se o agente, que comete o fato típico e ilícito, deve receber a devida punição.

Ainda, há que se falar nas excludentes de culpabilidade que são: aimputabilidade por doença mental, o desenvolvimento mental retardado, o desenvolvimento mental incompleto, a embriaguez acidental completa e ainda apotencial consciência da ilicitude através do erro de proibição. Além dessas, a exigibilidade de conduta diversa personificada através da coação moral irresistível ouobediência hierárquica à ordem não manifestamente ilegal.

Assim temos o posicionamento de Luiz Flavio Gomes:

O juízo de reprovação da culpabilidade (que é feito pelo juize que recai sobre o agente do fato punível que podia agir de modo diverso) tem por fundamentos: a capacidade do agente de querer e de entender as proibições jurídicas em geral (imputabilidade), a consciência da ilicitude do fato concreto (real ou potencial) e a normalidade das circunstancias do caso concreto (exigibilidade de conduta diversa). (2004, p.17)

\section{CONCLUSÃO}

Através do presente estudo, podemos observar que para que haja um crime, são necessários diversos aspectos formais e materiais a serem analisados em relaçãoa conduta do agente.

Podemos observar também, que ainda há discussões a respeito,principalmente no que se refere à culpabilidade, sobre o seu status de elemento constituinte do crime ou se deve ser analisada apenas como pressuposto de punibilidade.

Mesmo havendo bons argumentos para os dois lados o ordenamento jurídico brasileiro ainda vem adotando a teoria tripartida, no entanto, a teoria bipartida é mais moderna e alcança com êxito o objetivo de conceituar o crime de forma analítica, sendo a culpabilidade um elemento a ser analisado posteriormente como fator de punibilidade.

\section{METODOLOGIA}

O presente trabalho foi realizado através de pesquisa bibliográfica, artigos científicos e legislação vigente, a respeito do tema. 
Após realização de leitura de diversos artigos e literatura consagrada, bem como da legislação vigente, a respeito do tema abordado, foi realizada uma análise do conteúdo estudado e o mesmo foi sintetizado no presente trabalho

\section{REFERÊNCIAS}

GOMES, Luiz Flávio. Direito penal: parte geral. v3. São Paulo: RT, 2004.

JESUS, Damásio. Direito penal: parte geral, ed 36. São Paulo Saraiva. 2015.

BITENCOURT, Cezar Roberto. Tratado de Direito Penal: Parte Geral, v.I. ed 17. São Paulo: Saraiva, 2012. 